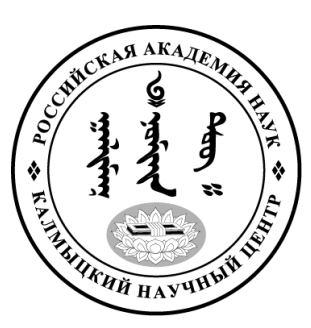

Published in the Russian Federation

Oriental Studies (Previous Name: Bulletin of the Kalmyk Institute for

Humanities of the Russian Academy of Sciences)

Has been issued as a journal since 2008

ISSN: 2619-0990; E-ISSN: 2619-1008

Is. 3, pp. 390-396, 2019

DOI: $10.22162 / 2619-0990-2019-43-3-390-396$

Journal homepage: https://kigiran.elpub.ru

УДК 39.395

\title{
Правила и нормы поведения, связанные с рождением ребенка, в традиционной культуре башкир
}

\author{
Розалия Рафкатовна Баязитова \\ ${ }^{1}$ Башкирский государственный педагогический университет им. М. Акмуллы \\ (д. За, ул. Октябрьской революции, Уфа 450000, Российская Федерация) \\ кандидат исторических наук, доцент \\ ORCID: 0000-0002-5731-2019. E-mail: rosali8@mail.ru
}

\begin{abstract}
Аннотация. Введение. В статье рассматриваются поведение беременной, особенности включения младенца в семью и социум в рамках традиционной культуры башкир. Целью исследования является определение правил, регламентирующих поведение беременной и ее близких в дородовой и послеродовой периоды. Meтоды. В ходе исследования применялись описательный, сравнительно-исторический, типологический методы исследования. Результаты. При подготовке статьи применялся комплексный подход, предполагающий анализ научных трудов по фольклору, этнографии, материалов полевых исследований и опубликованных источников. Результаты исследования показывают, что категория «возраст» - важное составляющее культуры общения. Традиционный этикет, взаимоотношения людей в социуме строились с учетом возрастных особенностей. В традиционной культуре башкир здоровье матери и ребенка было обусловлено соблюдением дородовых и послеродовых обрядов, которые программировали, закладывали желаемые нормы поведения в семье и обществе. На каждом этапе взросления человек получал покровителя, наставника со стороны семейного коллектива, общества. В традиционной культуре особенное значение придавали имянаречению. Имена были проводниками добра и зла, прогнозировали будущее человека. Закрепленное сразу после рождения, имя выполняло защитную, предсказательную, информативную функции. Bblводы. Материалы исследования показывают, что в традиционном обществе приобщение младенца к семье и обществу происходило на основе древних воззрений, мусульманской религии и представлений башкир о возрастной периодизации. Период до сорока дней регламентировался строгими запретами и предписаниями. В течение этого времени происходило «очеловечивание» нового члена социума: ребенок обретал покровителей, получал имя, наделялся атрибутами этого мира.

Ключевые слова: традиционный этикет башкир, возраст, младенец, запреты и предписания Для цитирования: Баязитова Р. Р. Правила и нормы поведения, связанные с рождением ребенка, в традиционной культуре башкир. Oriental Studies. 2019;(3): 390-396. DOI: 10.22162/26190990-2019-43-3-390-396.
\end{abstract}


UDC 39. 395

\title{
Childbirth Related Rules and Standarts of Conduct in Bashkir Traditional Culture
}

Rozaliya R. Baiazitova ${ }^{l}$

\author{
${ }^{1}$ Akmullah Bashkir State Pedagogical University (3a, Oktyabrskoy Revolutsii Str., Ufa 450000, \\ Russian Federation) \\ Cand. Sc. (History), Associate Professor \\ ORCID: 0000-0002-5731-2019. E-mail: rosali8@mail.ru
}

\begin{abstract}
Introduction. The article examines behavioral patterns of pregnant women, introduction of a newborn into the family and community within the framework of traditional Bashkir culture. The goal of the research is to delineate rules to be observed by a pregnant woman and her relatives in prenatal and postnatal periods. Methods. The research applies descriptive, comparative historical, and typological methods. Results. The work employs a comprehensive approach which includes analyses of scholarly papers in folklore studies, ethnography, collected field data, and available publications. The obtained results show that the category of age constitutes an essential part in the culture of communication. In traditional society, individual behavior and social contacts were largely determined by age. Each nation has its own perception of time, and traditional etiquette is closely related to such representations. In the traditional culture of Bashkirs, the health of mother and child was believed to be determined by whether certain prenatal and postnatal rituals, rules of conduct and etiquette established by transition ceremonies were observed. The first days of a child's life witnessed quite a number of ceremonies connected to the 'for-the-first time' category; once the latter were duly observed, the status of the newborn was fixed, established, and corresponding rules of conduct defined. That was accompanied by the use of material, verbal and nonverbal means of influence on the baby. The numerous ceremonies performed since the first days were programmed to delineate somewhat required standards of behavior in the family and society. At each stage of the child's way into adulthood he / she was patronized and mentored by a family or community member. Similar ties were established with those who took part in the shaving of prenatal hair, cutting of fetters, witnessed the emergence the first milk tooth, etc. So, subsequently in everyday life the child communicated with the latter as if those were close relatives. Such individuals had the right to instruct the child, deliver sermons, and ask for his / her help. In traditional culture, special significance was attached to the name-giving ceremony. Names were viewed as conductors of good and evil believed capable of determining an individual's future. Once fixed right after the birth, the name performed protective, predictive, and informative functions. It was closely connected with moral and aesthetic qualities of the individual. Subsequent changes in status resulted in that the individual gradually lost his / her given name, and people around replaced it with terms of relationship. On the one hand, names performed a protective function, and on the other hand, proved a most vulnerable part of personality, which is attested to by the ban on pronouncing personal names as such. Conclusions. The examined research materials show that in traditional society the introduction of a newborn into family and society was based on ancient views, Moslem doctrine, and life-cycle representations of the Bashkirs. The first forty days of life were regulated by strict bans and instructions. Those were days of bidding farewell to signs of 'otherness': they buried the afterbirth, made an amulet of the umbilical cord, etc. During the period the new member of the community was being hominified', i.e., the child acquired patrons, received a name, and was granted attributes of the external world.
\end{abstract}

Keywords: traditional etiquette of Bashkirs, age, newborn, bans and instructions For citation: Baiazitova R. Childbirth Related Ruled abd Standarts of Conduct in Bashkir Traditional Culture. Oriental Studies. 2019;(3): 390-396. DOI: 10.22162/2619-0990-2019-43-3-390-396. 
Введение. Возраст - важное составляющее культуры общения. Традиционный этикет, взаимоотношения людей в социуме строились с учетом возрастных особенностей. Ощущение времени у разных народов заметно отличается. Ф. Г. Хисамитдинова отмечает, что «вакыт» - «одна из категорий мифологической картины мира. Башкиры различают природное и жизненное время. Природное время состоит из солнечных и лунных циклов: көн 'день', ай 'месяц', көндөз 'днем', төн 'ночь' и др. Жизненное время также имеет свои циклы: бала сак 'детство', йәш сак 'молодость', егет сак 'молодость', карт сак 'старость' и др.» [Хисамитдинова 2010: 81]. Поведение в семье и обществе регламентировалось согласно установленной номинации.

В традиционной культуре башкир персональное время было обусловлено различными обрядами, проводимыми в рамках семьи. Развитие ребенка и становление его личности отмечались посредством обрядов перехода, и для него устанавливались нормы поведения в обществе.

Согласно А. К. Байбурину, в жизненном пути человека биологически четко определены лишь начало и конец. Все остальные этапы не имеют отчетливых границ. Мы не можем на основании биологических критериев сказать, что именно с этого времени человек стал взрослым или стариком. Эта «недоработка» природы исправляется с помощью ритуала. Благодаря обрядам жизненный путь разбивается на определенные этапы. Разумеется, для этих обрядов существуют биологические предпосылки, но конкретные границы устанавливаются искусственно. Аналогичным образом сегментируется время. Вероятно, именно с помощью ритуалов человек вышел из плена континуальности и создал свое (искусственное, социальное) время, воплотившееся в различного рода календарных системах [Байбурин 1995: 21]. Поэтому в традиционном обществе значимые возрастные (социальные) изменения были в центре внимания семьи, общества. «Соответственно, переход из одной возрастной категории в другую обозначал смену социального статуса. Возрастная терминоло- гия и периодизация жизненного цикла в этнической культуре определены представлениями о возрастной стратификации и времени в целом. При этом возрастной символизм включает универсальные и этнически-специфические составляющие», - считает Э. П/ Бакаева [Бакаева 2014: 89]. Мифологически эти переходы означали смерть в одном качестве и возрождение в другом.

В данной статье рассмотрим правила, регламентирующие поведение беременной, ее родных, близких в дородовой, послеродовой периоды и особенности включения младенца в семью, социум в целом.

Результаты исследования. Возрастная периодизация у башкир охватывала период с момента зачатия до момента смерти. O благополучии ребенка начинали заботиться задолго до его рождения. По поверьям, здоровье ребенка и матери, наряду с другими условиями, было обусловлено соблюдением традиционных норм этикета. Согласно сообщениям наших информантов, обычно женщины из-за боязни сглаза и стыдливости до последнего момента скрывали беременность, не показывались посторонним, особенно мужчинам.

На основе многолетнего опыта были выработаны правила поведения и запреты для беременных: не показываться в людных местах, не есть спаренные ягоды, желтки яиц, не смотреть на вырубленные деревья, обломанные ветки, не садиться на холодное или, наоборот, горячее место, не смотреть на забитых животных, убитых зверей, не поднимать тяжелое, не готовить пищу, не выходить на улицу после заката солнца, не точить нож, косу, не ограничивать себя в желаемой пище, не сидеть на пороге, не находиться возле покойника [Султангареева 2003: 39-42]. По поверьям башкир, нарушение этих правил могло нанести вред ребенку. Например, если ребенок в 2-3 года не начинал ходить, то считали, что женщина в период беременности ударила собаку [Башкорт халык 1995: 71].

В отдельных случаях в запретах даются конкретные объяснения необходимости соблюдения существующих ограничений. Например: нельзя принимать участие в похо- 
ронно-поминальной обрядности, в противном случае ребенок может умереть; нельзя смотреть на искалеченных животных, ребенок может родиться некрасивым и т. п.

Соблюдение запретов на визуальные и реальные контакты, временные и пространственные ограничения были направлены на то, чтобы обеспечить благополучное течение беременности, предотвратить выкидыш, неправильное развитие плода. Иными словами, от поведения беременной в повседневной жизни зависело будущее ребенка: физическое и психическое здоровье, внешность и способности, характер и поведение.

Жизненный цикл человека начинается с момента рождения и сопровождается многочисленными обрядами. В традиционной башкирской культуре строго соблюдались следующие обряды и обрядовые действия, связанные с периодом детства: обрезание пуповины (кендек кисеу), захоронение последа (бала артыл күмеү), первое кормление (ауызландырыу), первое купание новорожденного (беренсе тапкыр йыlyындырыу), укладывание в колыбель (тәүге тапкыр бишеккә haльly), наречение колыбельным именем (бишек исеме кушыу), наречение именем с приглашением муллы (исем кушыу), сбривание утробных волос (карын сәсен альуу), первое представление обществу (бәпес күреу / күрһәтеу), появление первого молочного зуба (теш котлау), перерезание пут (mыıмау кисеу) и т. д.

Необходимо отметить, что многие обрядовые действия, праздники привязаны к временной единице «в первый раз». Т. В. Цивьян в качестве самостоятельной единицы выделяет указание впервые, в первый раз. Оно, во-первых, может маркировать начало определенного временного периода. Обычно это весна, т. е. начало светового года, обновления природы, когда человек впервые видит проснувшихся, прилетевших, вышедших и т. п. животных, птиц, насекомых и по ним предсказывает текущий год. Например, если увидишь одну ласточку, значит, все лето будешь одиноким. Во-вторых, так маркируется действие, совершаемое в первый раз в отмеченные моменты (действия, связанные с новорожденным и т. п.). Например, когда мать в первый раз дает ребенку грудь, пусть не держит его левую руку, чтобы он не стал левшой [Цивьян 2009: 129-130].
Раннее детство насыщено обрядами и правилами, обусловленными со значимой в традиционной культуре башкир единицей времени «впервые, в первый раз». По сегодняшний день возрастные (физиологические, психологические) особенности ребенка, зафиксированные впервые, закрепляются обрядом, маркируют его положение в семье.

Приобщение новорожденного к социуму происходило в ходе обрядов перехода, где устанавливались статус индивида и желаемые нормы поведения, правила обращения с ним. При этом применялись вещественные, вербальные и невербальные средства воздействия на ребенка. «В пожеланиях содержатся поэтические изложения правил и норм поведения. Вместе с первой же пищей человек приобщается к этикету, морали общины», - отмечает Р. А. Султангареева [Султангареева 1998: 34]. Например, во время первого купания повитуха, слегка обдавая парным веником ребенка, приговаривала:

Стань крепким парнем,

Крепким, как камень,

И крепче камня!

Толще бревна!

С матерью рядом расти и отцом,

Пусть слово твое будет мудрым всегда,

Пусть лик твой прекрасный не старят года,

Пусть руки твои не страшатся труда!

[Башкирское народное ... 2010: 284].

Обряды, проводимые с первых дней рождения ребенка, программировали, закладывали желаемые нормы этикета в семье и обществе.

На каждом этапе взросления в процессе проведения обрядов перехода человек получал покровителя, наставника со стороны семейного коллектива, общества. Повитуха, принимавшая роды, считалась при этом как бы второй матерью родившихся и всегда пользовалась вниманием со стороны семьи, детей, которых она принимала. На связь повитухи с ребенком указывает и термин для обозначения повивальной бабки - кендек индй 'пуповая мать', кендек әбей, кендекәй 'пуповая бабка'. Считалось, что ребенок характером будет походить на повитуху. Повивальная бабка на всю жизнь сохраняла тесную связь со своим восприемником [Бикбулатов, Фатыхова 1991: 89]. 
Человек, первым обнаруживший появление молочного зуба ребенка, становился теш атай - «зубным отцом». Этот статус закреплялся путем взаимного одаривания. Подобные связи устанавливались и с теми, кто принимал участие в изготовлении колыбели, «продаже ребенка», подборе (рекомендации) имени, стрижке утробных волос, разрезании пут и т. п. Эти узы закреплялись также путем дарообмена. В дальнейшей повседневной жизни с ними общались как со своими родственниками, близкими сородичами. Каждый из них помогал ребенку, имел право давать наставления, поучения как своему подопечному, просить его о помощи.

Башкиры, как и другие народы, не представляли себе человека без имени. Наречение имени в традиционных культурах было, без сомнения, основной формой моделирования социального статуса. Не случайно в тюркских языках термин ат обозначал не только «имя», «название», «наименование», но и «славу», «известность», «честь», «репутацию» [Традиционное мировоззрение ... 1989: 170].

Во всех культурах имянаречению придавали большое значение. У башкир сразу после рождения ребенка повитуха нарекала его временным пеленочным именем. По представлениям башкир, имя являлось защитой от злых духов. Постоянное имя младенец получал после проведения специального праздника, с приглашением муллы и чтения молитвы (азан). Обряд имянаречения проводился до сорока дней после рождения ребенка.

На имя возлагались определенные функции, и у каждого народа были свои особенности имянаречения. Например, у чувашей известно более 11 тыс. имен-благопожеланий, отмечает Г. Н. Волков. Смысл многочисленных русских имен - Любомир, Владимир, Святослав, Любомудр, Ярославна и т. п. - общеизвестен. Имя Надежда заключает в себе не только утверждение «Ты наша надежда», но и благословение: «Будь нашей надеждой и опорой» [Волков 1999: 52-53]. В народе верили, что имя влияет на судьбу его обладателя, поэтому имена выбирали с глубоким смыслом и особым значением.

У башкир встречались тюркские, персидские, арабские, частично монгольские имена. В них вкладывали желаемые нрав- ственные и физические качества, характеристики личности, старались называть детей именами известных, достигших в жизни определенных успехов людей. Прежде чем назвать именем уважаемого человека, спрашивали у него разрешения, в отдельных случаях одаривали.

В народе считали, что продолжительность жизни, благополучие зависят отчасти и от имени. По словам информантов, короткие имена предвещают непродолжительную жизнь. Компоненты ай, көн, таң, гөл, сәскә обозначали эстетические, булат, тимер, батыр - физические, бай, хан - социальные характеристики обладателя имени. Имена означали небесные светила, определенные качества людей.

Чтобы оградить ребенка от смерти, его нарекали именами Үлмәсбикә 'неумирающая', Ишбулды 'стал напарником'; в случае смерти предшествующего младенца - Яныл 'обновись'; чтобы обмануть злого духа - Яманкыз 'плохая девочка'; в случае смерти матери или отца - Бүләк 'подарок', Mupaç 'подарок, наследство' [Бикбулатов, Фатыхова 1991: 105-106].

Имена Игез̧бай, Кинйәбай говорят о том, что первый является одним из двойни, а второй - последним ребенком в семье. Оберегательно-охранительное значение имело наречение новорожденных именами с основой aŭыy: Айыухан, Айыусы, Айыубай [Илимбетова 2006: 196].

В традиционной культуре имена были проводниками добра и зла, прогнозировали будущее человека. Со сменой статуса человек постепенно «терял» собственное имя, окружающие заменяли его на термины родства. С одной стороны, имена выполняли охранительную функцию, с другой — являлись наиболее уязвимой частью человека. Об этом свидетельствует широко распространенный запрет на произнесение личных имен. Закрепленное сразу после рождения, имя выполняло защитную, предсказательную, информативную функции. Оно тесно связано с моральными и эстетическими качествами личности. Своими поступками человек мог прославить и опозорить собственное имя. Являясь частью человека, имя охранялось табуированием как при жизни, так и после смерти.

Свое имя, как правило, младенец получал до сорока дней. В культуре многих на- 
родов период до сорока дней считался опасным как для матери, так и для младенца. В доме новорожденного весь этот период поддерживали огонь в очаге, не тушили свет, рядом с ребенком оставляли обереги - нож или ножницы. Роженице в это время нельзя было готовить еду или появляться на людях. Первые три дня роженице полагалось не вставать с постели, а домашнюю работу за нее выполняли мать или свекровь, другие родственницы, в случае их отсутствия повитуха [Фатыхова, Галиева 2016: 344].

В целях защиты ребенка до 40 дней ребенка нельзя показывать посторонним людям, оставлять дома одного. Некоторые комментарии к запретам показывают опасения народа, внушают необходимость обязательного их соблюдения: «Нельзя любоваться новорожденным, младенцем - сглазишь», «Нельзя хвалить младенца - сглазишь, малыш заболеет», «Нельзя дома оставлять одного - может подменить шайтан» и т. п.

В период приобщения младенца к социуму, до сорока дней, нельзя было совершать с ребенком действия, использовать атрибуты, характерные для «очеловеченного» мира.

Подобные представления бытовали и у казахов. Только после окончания первого сорокодневья жизни ребенка на детскую одежду, сменяющую первую рубашку um-көйлек, нашивали различные обереги (перья филина, треугольные кожаные футляры тұмар с отрывками коранического текста и т. п.); когда ребенок начнет улыбаться, на руку надевался браслетик от сглаза көзмоншақ из стеклянных бусинок в форме глаз. На головной убор ребенка через 2-3 месяца прикрепляли перья филина ( $\gamma \kappa i)$ [Шаханова 1998: 51].

Строгое соблюдение предписаний и запретов Ж. Т Ерназаров объясняет следующим образом: «По мнению информаторов, при рождении кости у ребенка расслабленные, он не адаптирован к жизни. Период 40 дней после рождения призван адаптировать ребенка к новым условиям, у него должны окрепнуть кости, он(а) должен привыкнуть к внеутробной жизни, которую ребенок воспринимает как шок после рождения. Существует и другое мнение, что младенец, как „посланец иного мира“, родившись, становится подверженным влиянию потусторонних сил» [Ерназаров 2003: 98].
До окончания сорока дней ребенок не считался полноправным членом семейного коллектива, социума. Обряды, запреты и предписания были направлены на обеспечение безопасной адаптации к новым условиям жизни. Возможно, все эти опасения, наряду с заботой о здоровье ребенка и матери, мифологически были связаны с представлениями древних о душе. Многие народы считают, что переход души из этого мира в иной и наоборот по времени равен 40 дням. В течение 40 дней младенец находится в переходном состоянии, в него вселяется душа. Исходя из этого можно объяснить отдельные правила поведения. Необходимо отметить, что, например, особая забота о душе покойного проявлялась сразу после смерти: закрывали зеркала, не гасили свет в доме умершего в течение сорока дней и др. По сегодняшний день соблюдается предписание завешивать в доме зеркала, чтобы душа покойного не застряла в них. По представлениям многих народов, зеркало имеет символическое значение, является пограничным предметом, обозначающим вход в потустороннее пространство. Об этом свидетельствуют и другие запреты, сохранившиеся среди башкир: Көзгөгә күn карарzа ярамай, картаяһьц 'Нельзя много смотреть в зеркало, быстро состаришься', Йәш балага көзгөнө күрһәтергә ярамай 'Младенцам нельзя показывать зеркало').

Заключение. Внутриутробное развитие плода, первые дни младенца до сорока дней считались наиболее опасными для матери и ребенка, поведение регламентировалось строгими запретами и предписаниями. В это время происходило приобщение ребенка к семье, социуму, «прощались» с признаками «инаковости»: хоронили послед, «рубашку», делали оберег из пуповины, сбривали утробные волосы и т. п. В течение сорока дней происходило «очеловечивание» нового члена социума: ребенок обретал покровителей, получал имя, наделялся атрибутами этого мира. Приобщение младенца в жизнь семьи происходило согласно традиционным представлениям о возрасте, древним воззрениям и религии.

\section{Источники}

Башкирское народное ... 2010 - Башкирское народное творчество. Т. 12: Обрядовый фольклор. Уфа: Китап, 2010. 592 с. 
Башкорт халык 1995 - Башкорт халык ижады: Йола фольклоры. Өфө: Башкортостан «Китап» нәшриәте, 1995. 560 бит.

\section{Sources}

[Bashkir Folk Art. Vol. 12: Ceremonial Folklore]. Ufa: Kitap, 2010. 592 p. (In Russ.)

[Bashkir Folk Art: Ceremonial Folklore]. Ufa: Kitap, 1995. 560 p. (In Bash.)

\section{Литература}

Байбурин 1995 - Байбурин А. К. Семиотические аспекты функционирования традиционной культуры восточных славян: автореф. дис. в виде научного доклада на соискание уч. ст. д-ра ист. наук. СПб., 1995. 32 с.

Бакаева 2014 - Бакаева Э. П. Об обозначении возрастных категорий в культуре ойратов и калмыков // Вестник Калмыцкого института гуманитарных исследований РАН. 2014. № 4. С. 89-95.

Бикбулатов, Фатыхова 1991 - Бикбулатов Н. В., Фатыхова Ф. Ф. Семейный быт башкир. XIX-XX вв. М.: Наука, 1991. 189 с.

Волков 1999 - Волков Г. Н. Этнопедагогика: Учеб. для студ. сред. и высш. пед. учеб. заведений. М.: Академия, 1999. 168 с.

Ерназаров 2003 - Ерназаров Ж. Т. Семейная обрядность казахов: символ и ритуал. Алматы: Курсив, 2003. 200 с.

Илимбетова 2006 - Илимбетова А. Ф. Культ медведя в религиозно-мифологической системе башкир // Восток в исторических судьбах народов России. Книга 3. Мат-лы $\mathrm{V}$ Всероссийского съезда востоковедов (г. Уфа, 16-17 сентября 2006 г.). Уфа: Вилли Окслер, 2006. С. 194-196.

Султангареева 2003 - Султангареева Р. Семейно-бытовой обрядовый фольклор башкир // Ватандаш. 2003. № 3. С. 38-43.

Султангареева 1998 - Султангареева Р. А. Семейно-бытовой обрядовый фольклор башкирского народа. Уфа: Гилем, 1998. 243 с.

Традиционное мировоззрение ... 1989 - Традиционное мировоззрение тюрков Южной Сибири. Человек. Общество / Львова Э. Л., Октябрьская И. В., Сагалаев А. М., Усманова М. С. Новосибирск: Наука. Сиб. отд-ние, 1989. $243 \mathrm{c}$.

Фатыхова, Галиева 2016 - Фатыхова Ф. Ф., Галиева Ф. Г. Обряды, связанные с рождением ребенка // Башкиры / отв. ред. Р. Г. Кузеев, Е. С. Данилко. М.: Наука, 2016. С. 337-355.

Хисамитдинова 2010 - Хисамитдинова Ф. Г. Мифологический словарь башкирского языка. М.: Наука, 2010. 452 с.

Цивьян 2009 - Цивьян Т. В. Модель мира и ее лингвистические основы. Изд. 4-е. М.: ЛИБРОКОМ, 2009. 280 с.

Шаханова 1998 - Шаханова Н. Мир традиционной культуры казахов (этнографические очерки). Алматы: Казахстан, 1998. 184 с.

\section{References}

Bakaeva E. P. To the issue of denoting age categories in the Oirat and Kalmyk cultures. Bulletin of the Kalmyk Institute for Humanities of the RAS (Oriental Studies). 2014. No. 4. Pp. 89-95. (In Russ.)

Bayburin A. K. [Traditional Culture of the East Slavs: Semiotic Aspects of Functioning]. A Dr.Sc. (history) thesis abstract. St. Petersburg, 1995. 32 p. (In Russ.)

Bikbulatov N. V., Fatykhova F. F. [Family life of the Bashkirs: 19 ${ }^{\text {th }}-20^{\text {th }} \mathrm{cc}$.] Moscow: Nauka, 1991. 189 p. (In Russ.)

Ernazarov Zh. T. [Kazakh Family Rites: Symbol and Ritual]. Almaty: Kursiv, 2003. 200 p. (In Russ.)

Fatykhova F. F., Galieva F. G. Birth-related rites. In: [The Bashkirs]. R. G. Kuzeev, E. S. Danilko (eds.). Moscow: Nauka, 2016. Pp. 337-355. (In Russ.)

Ilimbetova A. F. A religious and mythological system of the Bashkirs: the bear cult. In: [The East in the Historical Fate of Russia's Peoples]. Book 3. Congr. proc. (Ufa, September 16-17, 2006). Ufa: Villi Oksler, 2006. Pp. 194-196. (In Russ.)

Khisamitdinova F. G. [A Mythological Dictionary of the Bashkir Language]. Moscow: Nauka, 2010. 452 p. (In Russ.)

Lvova E. L. et al. [Traditional Worldviews of South Siberian Turks. Person. Society]. Novosibirsk: Nauka, 1989. 243 p. (In Russ.)

Shakhanova N. [A World of Kazakh Traditional Culture: Ethnographic Sketches]. Almaty: Kazakhstan, 1998. 184 p. (In Russ.).

Sultangareeva R. Family and household ceremonial folklore of the Bashkirs. Compatriot. 2003. No. 3. Pp. 38-43. (In Russ.)

Sultangareeva R. A. [Family and Household Ceremonial Folklore of the Bashkir People]. Ufa: Gilem, 1998. 243 p. (In Russ.)

Tsivyan T. V. [A Model of the World and Its Linguistic Roots]. $4^{\text {th }}$ ed. Moscow: LIBROKOM, 2009. 280 p. (In Russ.)

Volkov G. N. [Ethnopedagogics]. A textbook for pedagogical university and college students. Moscow: Akademia, 1999. 168 p. (In Russ.) 